\title{
Experimental Study on Mechanical Behavior of Hinged Joint in Assembly Hollow Slab Bridge
}

\author{
WU Hou-xuan ${ }^{1}$, WANG Jian ${ }^{1}$, YI Han-bin ${ }^{2}$ and JIANG Xiang-lin ${ }^{2}$ \\ 1 Jiangxi GANYUE Expressway Limited Company, Nanchang, Jiangxi, China \\ 2 Jiangxi transportation institute, Nanchang, Jiangxi, China
}

\begin{abstract}
Keywords: hollow slab; hinge joint; mechanical behavior; prototype test
Abstract: Using an opportunity of reconstruction of a assemble PC hollow slab bridge, the mechanical behaviour of a hinged joint and hollow slab under vehicle loads are discussed is this paper, such as the cracking load and load transmitting performance. The results show that the cracks occurred in the bottom of the beam when the offset load reached $365 \mathrm{kN}$ (1.3 times of a vehicle load), and concrete of roof tend to be crushed with load increasing to $500 \mathrm{kN}$ (2.0 times of a vehicle load). During the whole loading process, the shallow hinge joint structure has not been cracked, which showed good shear transfer performance. In addition, based on the principle of solving the internal force of hinged joint under the vehicle load, the theoretical and experimental results show that shear hinge joint has strong bearing capacity, the test can reflect that the failure mode of hinge joint in the assembled hollow slab is not caused by shear stress.
\end{abstract}

\section{Introduction}

The assembled hollow slab with shallow hinges began to be used in the 1970s. Since the 1990s, the shallow hinge structure has gradually been abandoned and the deep hinge structure has been replaced. According to statistics, China's medium and small span of 20 meters below the road bridge basically uses the hollow plate structure. After the assembly of hollow slab bridge after decades of operation, due to hinge joint design and construction of inherent defects, coupled with vehicle overloading, environmental erosion and other factors. At present, a large number of hollow slab bridges, especially shallow hinged hollow slabs appear hinge cracking problems, eventually forming a "veneer compression" phenomenon.

Hinge joint disease has seriously affected the safety of fabricated hollow slab bridges and the development of the bridge. Therefore, a lot of researches have been done on the mechanics and failure mechanism of joint hinges by domestic scholars. Representatively, Ye Jianshu designed a test for testing the shear resistance of reamed joints, and proposed the joint shear strength And the bearing capacity of the calculation formula; different forms of joint-type joints and hinge joints of reinforced hollow plate model tests were conducted by Yong feng, Wang Tiecheng, Tang Xianxi, the main conclusions as follows: 1) As the joint height increases, the transverse connection between adjacent plates also increases. 2) The fatigue load is a major factor of shallow joint failure. 3) Reinforcement relative to the hinge joints without reinforcement in the hinged way to improve the ability to transmit load hinge joints. Wang Qiu and Wu Qingxiong designed and fabricated a full span hollow bridge model with a deep 8-meter-span structure. The test results showed that: 1) when loading to $70 \mathrm{kN}, 1.0$ times the designed vehicle load (Highway-I load, the joints are cracked with the joint of the hollow slab; 2) The joint is in the mode of bending failure with the load added to $140 \mathrm{kN}$ (2.0 times the designed vehicle load) and the crack penetrates to the top of the joint to form a through seam.

There are few studies on the mechanical behaviours and failure modes of shallow hinge joints under vehicle loads. There is still no conclusion about the failure mechanism of hinge joints. Although hollow slab beams with shallow hinge joints are no longer used in design, there are still a large number of such hollow slab bridges in operation. Whether the bearing capacity of shallow hinge joints is really "vulnerable" is worth further exploration, and for the rational use of such structures and reinforcement transformation also has important practical significance. In this paper, two prestressed concrete hollow slabs with a span of $20 \mathrm{~m}$ (with shallow hinge joints) were used as test objects to study the mechanism of the mechanics of shallow hinge joints under vehicle load. 


\section{Prototype test design}

Taking advantage of the opportunity of demolition and reconstruction of a fabricated hollow slab bridge in a reconstruction and extension project, 6 prototype beams were checked from the field to the laboratory. Two mid plates were selected to form a test model.

Each hollow slab prefabricated width $155 \mathrm{~cm}$, height $90 \mathrm{~cm}$, top and bottom thickness of $10 \mathrm{~cm}$, web thickness $11 \mathrm{~cm}$. Each plate has 15 ASTM A416-90a 270 (0.6 inches in diameter) steel hinge (as Fig 1), the hollow plate with C40 concrete.

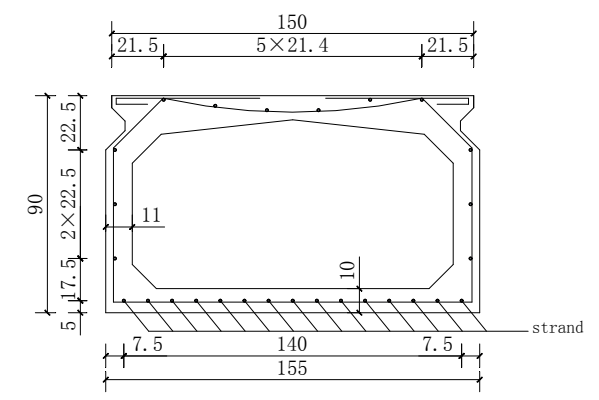

Fig.1 Mid-span section of wide hollow slab/cm

Shallow hinge joint size shown in Fig 2 (a) below. Hollow plate embedded in the connection of steel N1, the steel along the longitudinal bridge spacing of $10 \mathrm{~cm}$ layout, the specific structure shown in Fig 2 (b). There are two kinds of hinge joints, including the scissors bar N2 and the longitudinal bar $\mathrm{N} 3$ with a longitudinal spacing of $10 \mathrm{~cm}$, as shown in Fig 2 (c).

The hinges have been completely destroyed as the single hollow slab was checked in from the field to the laboratory. Before the test, the original concrete joints were completely cleaned, and some of the bridge deck paving layers were demolished, and then the blocks were suspended and placed on the supports (the test beam support type was a rubber bearing plate at one end and a PTFE sliding rubber support at the other end ), as shown in Fig 3. Reinforced with hinges after the use of C40-level concrete re-pouring joints and bridge deck pavement, concrete deck pavement thickness of $10 \mathrm{~cm}$, along the longitudinal beam every $10 \mathrm{~cm}$ arranged a layer of light-round steel. After curing for 28 days, the hinge test was performed. The completed test beam was shown in Fig 4 and the hollow plate and hinge number were shown in Fig 5.
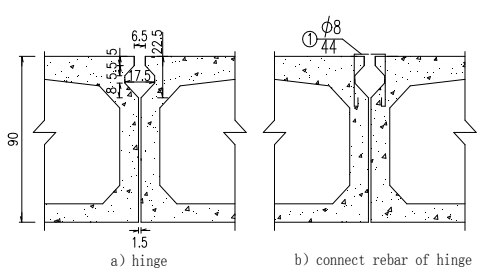

Fig.2 Hinge joint structure and reinforcement $/ \mathrm{cm}$

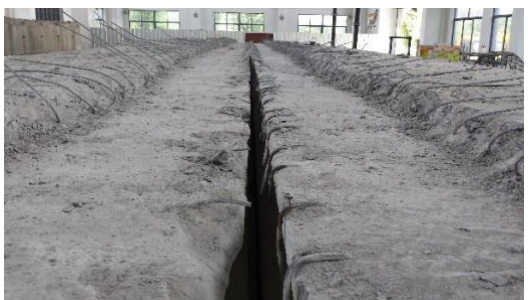

Fig.3 Hollow slab beam

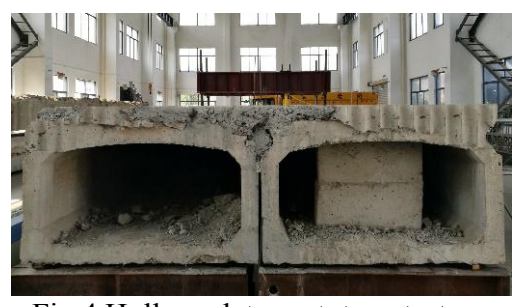

Fig.4 Hollow plate prototype test

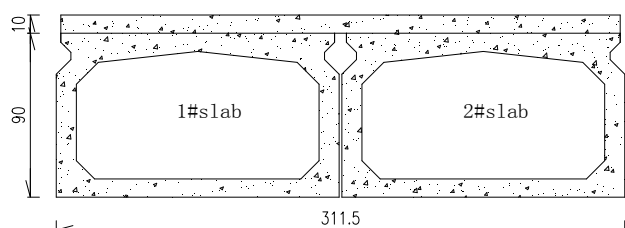

Fig. 5 Cross section of hollow plate $/ \mathrm{cm}$

\section{Test loading and measuring point arrangement}

Test loading

According to Section 4.3.1 (2) of "General Specification for Design of Highway Bridges and Culverts", the local load of bridge structure is calculated by using vehicle load. According to the most adverse principle of loading, the axle load of the standard vehicle after the load is converted into a uniform force acting on the test beam, and the two wheel loads act in the same transverse position. 
The ground area of the standard vehicle rear axle tire is determined according to "Design General Specifications "(JTG D60-2004) Table 4.3.1-2 value of $0.6 \mathrm{~m} \times 0.2 \mathrm{~m}$, the specific loading position shown in Fig 6.

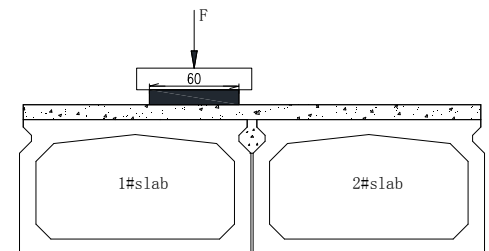

a)transverse direction

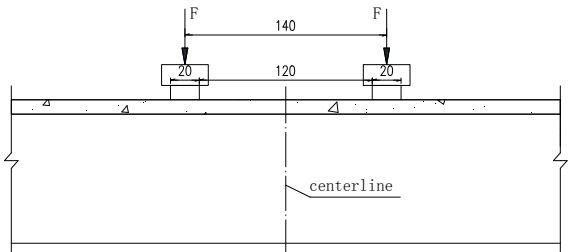

b) longitudinal direction

Fig.6 Vehicle loading position

Test hydraulic jack for two simultaneous loading, the relationship between load and design vehicle load shown in Table 1. Before the formal test, the hollow slab was preloaded to $140 \mathrm{kN}$. After checking whether all the measuring points had been put into normal working condition, the slab was unloaded to $0 \mathrm{kN}$ and then loaded again.

Table1 Value of Load and corresponding vehicle load

\begin{tabular}{|c|c|c|c|}
\hline $\begin{array}{l}\text { Load } \\
\text { value }\end{array}$ & $\begin{array}{c}\text { Vehicle load } \\
\text { (Highway-I } \\
\text { load) }\end{array}$ & $\begin{array}{c}\text { Load } \\
\text { value }\end{array}$ & $\begin{array}{c}\text { Vehicle load } \\
\text { (Highway-I } \\
\text { load) }\end{array}$ \\
\hline $70 \mathrm{kN}$ & 0.25 times & $350 \mathrm{kN}$ & 1.25 times \\
\hline $140 \mathrm{kN}$ & 0.50 times & $420 \mathrm{kN}$ & 1.50 times \\
\hline $210 \mathrm{kN}$ & 0.75 times & $490 \mathrm{kN}$ & 1.75 times \\
\hline $280 \mathrm{kN}$ & 1.00 times & $560 \mathrm{kN}$ & 2.00 times \\
\hline
\end{tabular}

Measuring point arrangement

In order to understand the effect of the hinge joint load transfer, hollow plate deflection measuring points arranged as shown in Fig 7, the longitudinal layout of the three cross-section, namely $\mathrm{L} / 4$ section, $\mathrm{L} / 2$ section and $3 \mathrm{~L} / 4$ section. The deflection point numbers of No. 1 board are D1-1, D1-2 and D1-3, and the deflection point numbers of No. 2 and No. 2 boards are D2-1, D2-2 and D2-3 in sequence.

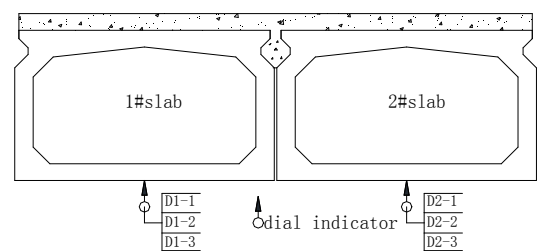

Fig.7 Deflection measuring points of hollow slab

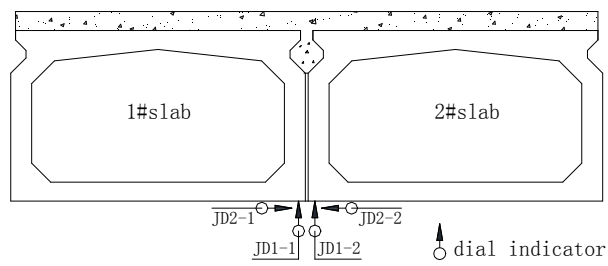

Fig.9 Displacement measuring points of hinge joint Fig.10 Strain measuring points of hinge joint

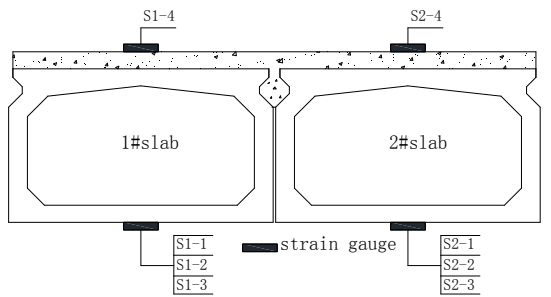

Fig.8 Measuring point hollow plate strain

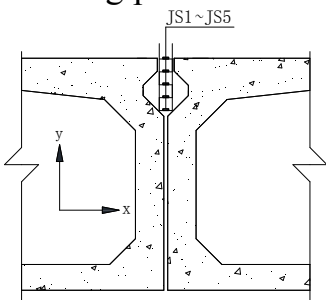

Hollow slab strain gauge measuring points along the longitudinal direction of the $\mathrm{L} / 4$ section, $\mathrm{L} / 2$ section and 3L/4 section, shown in Fig 8 . No. 1 hollow slab strain measurement points followed by the number of S1-1, S1-2, S1-3, S1-4 (across the roof), No. 2 plate strain measurement points followed by S2-1, S2-2, S2- 3, S2-4 (across the roof).

The relative displacement difference is an important index for evaluating the degree of hinge joint damage and its force transmission performance. In this experiment, four measuring points were arranged to measure the relative position change of the hinge joint. JD1-1 and JD1-2 measure the vertical Displacement, JD2-1, JD2-2 measuring the lateral displacement of the hinge joint, longitudinal bridge arranged in the cross-section, as shown in Fig 9. 
Before pouring the reaming concrete, the direction and strain measurement points of the hinge joint are pre-embedded, and only the $\mathrm{L} / 2$ section is arranged along the longitudinal bridge. The strain measurement points are numbered JS-1, JS-2, JS -3, JS-4 and JS-5, the specific arrangement is shown in Fig. 10.

\section{Test results and analysis}

The load-deflection curves and load-strain curves of the hollow slabs are shown in Fig. 11 and Fig. 12, respectively. In the initial stage of loading, the force is in the elastic phase. The load-deflection curves of the two plates change linearly and the rate of change is consistent. The joint between the joint and the beam is not cracked. When loaded to about $365 \mathrm{kN}$, that is 1.3 times to the designed vehicle load (Highway-I), bending cracks occur in the pure bending sections of No.1 and No. 2 hollow slabs. The structure begins to enter the elasto-plastic state and the rigidity decreases gradually. As load increases further, the load-deflection curves vary nonlinearly until loaded to $560 \mathrm{kN}$, or 2.0 times the designed vehicle load (Highway-I), and the concrete of roofs No. 1 and 2 approaches collapse. During the whole experiment, the crack of the hollow slab continues to develop. When it is loaded to $560 \mathrm{kN}$, the maximum width of the midspan crack reaches $5 \mathrm{~mm}$. However, the joint between the joint and the hollow slab does not crack during the whole experiment.
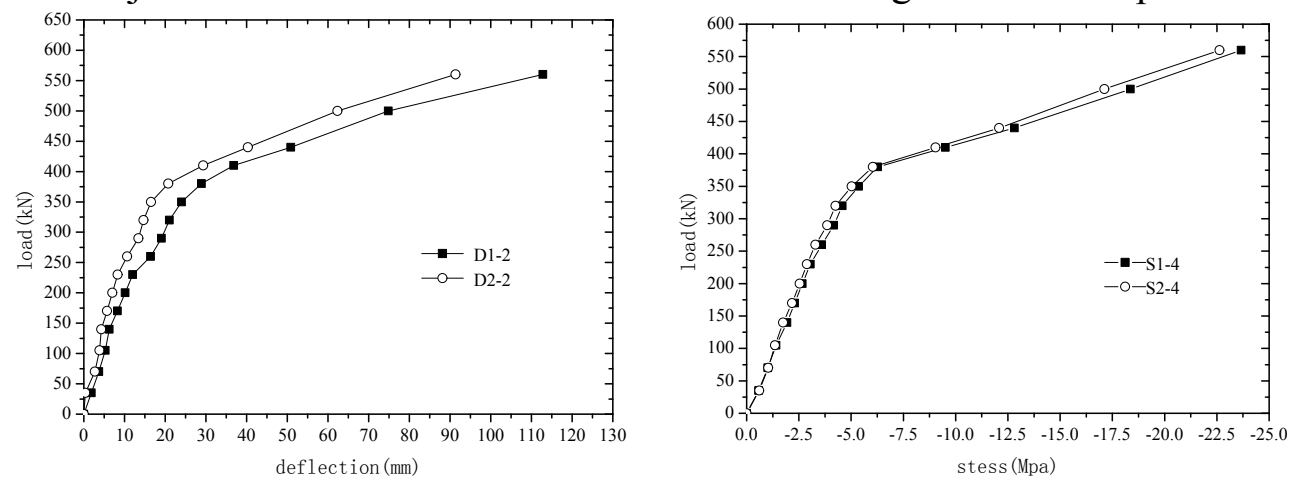

Fig.11 Load deflection curve of mid span section of hollow slab Fig.12 Load stress curve of mid span roof of hollow slab

$\mathrm{L} / 2$ section hinge joint transverse expansion and vertical displacement relative to the load changes as shown in Fig13 and Fig 14. It can be seen that the lateral expansion of the hinge joint and the vertical relative displacement during the whole loading process change linearly with the increase of load. When loaded to $560 \mathrm{kN}$, the horizontal opening is $0.153 \mathrm{~mm}$ and the vertical relative displacement is $0.201 \mathrm{~mm}$. After the end of the loading test, no cracked joints were observed.

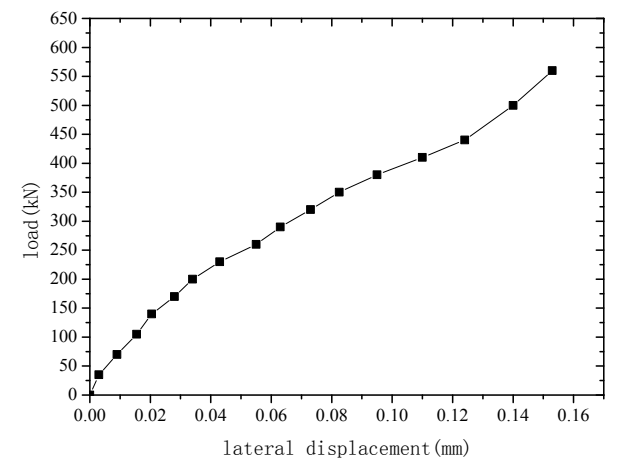

Fig.13 load lateral opening curve of hinge joint

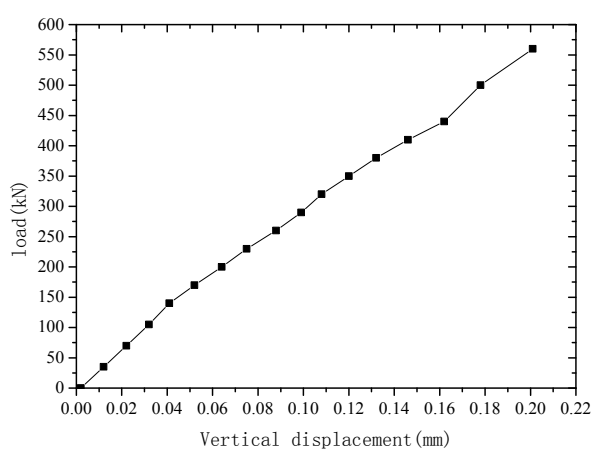

Fig.14 Vertical relative displacement curve of hinge joint

Transverse along the reaming section height strain measurement point JS1 $\sim$ JS5 horizontal stress values shown in Fig 15. Fig 15 show the loading process, the bottom hinge joint tension (JS1 JS4 measuring point), the upper compression (JS5 measuring point). As the load increases, the stress at the measuring point changes linearly. When the load reaches $560 \mathrm{kN}$, the tensile stress of JS1 at the bottom of the joint is $0.56 \mathrm{MPa}$. 


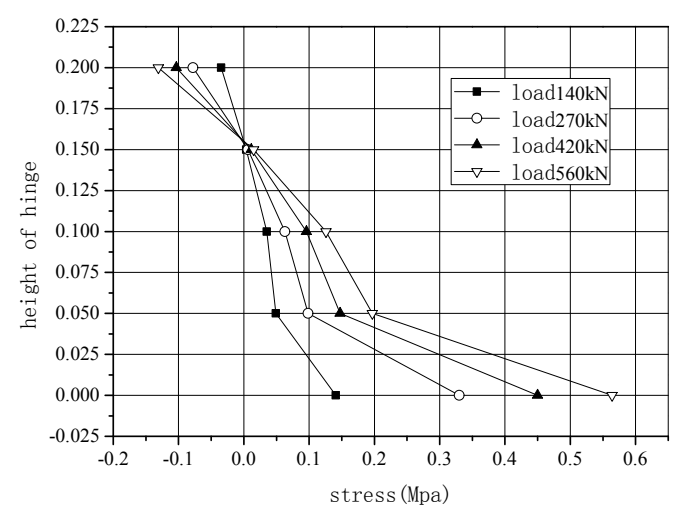

Fig.15 Transverse strain curves along the section height of hinge joint

\section{Shear bearing capacity calculation}

At present, China's relevant norms have not clearly how to shear joint calculation of shear joints. Shear resistance of joints is usually calculated according to the shear formula of concrete joints. The following formula lists the calculation formulas of the bridge workers in North America and China.

(1) United States Concrete Structure Design Code (ACI 318-05) Shear capacity calculation formula

$$
V_{n}=A_{v f} f_{y} \mu
$$

(2)Canadian highway bridge design specifications Canada Highway Bridges and Culverts in the design specifications of the joint surface shear strength formula is:

$$
v=\phi_{c}(c+\mu \sigma)
$$

(3) China's highway masonry and concrete bridge design (JTG D61-2005) [13] Highway bridge engineering design code Section 4.0.13 of the member is cut directly under the section, according to the following formula:

$$
\gamma_{0} V_{d} \leq A f_{v d}+\frac{1}{1.4} \mu_{f} N_{k}
$$

Taking the shallow reaming joint of this test as an example, the shear resistance and shear strength of the hinge joint are solved according to the above three specifications respectively. Based on the hinge plate principle, the joint shear stress and shear stress under 2.0 times the designed vehicle load are calculated (Detailed solution step reference 14). The above calculation results are shown in Table 3.

Table 3 Calculation of shear bearing capacity and strength of hinge joint

\begin{tabular}{|c|c|c|}
\hline Specification & $\begin{array}{c}\text { Shear } \\
\text { resistance/ } \\
\text { strength } \\
\text { value }\end{array}$ & $\begin{array}{c}\text { the joint shear } \\
\text { force(stress) in 2.0 } \\
\text { times the design of } \\
\text { vehicle load }\end{array}$ \\
\hline ACI318-5 & $V_{n}=88.4 \mathrm{kN}$ & $V_{d}=72.3 \mathrm{kN}$ \\
\hline CAN/CSA-S6-00 & $v=0.52 \mathrm{MPa}$ & $v_{d}=0.32 \mathrm{MPa}$ \\
\hline JTG D61-2005 & $A f_{d d}=558 \mathrm{kN}$ & $V_{d}=72.3 \mathrm{kN}$ \\
\hline
\end{tabular}

It can be seen from Table 3 that the joint shear strength and shear strength calculated by the three specifications are both greater than 2.0 times the calculated value of the joint shear under the action of vehicle load (Highway-I). Among them, the values of the calculated values in the United States and Canada are close to each other. The calculated shear capacity of China is far greater than that of the joint design. This is because the design value of direct shear strength of concrete in our country is given in Table 2. The shear failure of the actual reamed concrete depends on the shear strength of the joint surface between the old joint and the new one. 


\section{Conclusions}

(1) Two prestressed concrete hollow slabs with a span of $20 \mathrm{~m}$ (with shallow hinge joints) were used as the test objects to carry out the experimental study of the shallow hinge joint structure under the vehicle load. The shallow hinge is mainly shear under the partial load and the tensile stress at the bottom is smaller. The experimental results and test phenomena of the transverse stress, the transverse opening and the vertical relative displacement of the joints show that no cracking occurred under the design vehicle load (Highway-I) loaded to 2.0 times.

(2) According to the theoretical calculation results of ACI318-5 in the United States, CAN/ CSA-S6-00 in Canada and JTG D61-2005 in China, it can be seen that the shallow hinge structure has better performance of shear capacity, JTG D61-2005 of our country is more suitable for the calculation of shear strength of joint joints considering factors such as the roughness of joint surface, the sequence of application of concrete and the material characteristics.

(3) Through the test and theoretical calculation results, we know that the shear failure mode does not appear in the joint structure under 2.0 times of highway -I partial offset load. In the actual project, the shallow joints are in complex stress state of bending, pulling and shearing, the joints are easy to crack and form the phenomenon of "veneer stress", which is mainly caused by the insufficient flexural strength of the joints between the joints and the hollow slabs. However, in this test, the shear joint of the joint is mainly dominated, and the bending action of the joint is very small. Therefore, no damage occurs to the shallow joint, which indirectly verifies whether the joint crack is controlled by the bending stress of the joint. It is recommended that some structural and reinforcement measures be taken to improve the tensile load carrying capacity of the joints between the joint and the hollow slab.

\section{Acknowledgements}

The authors would like to acknowledge the financial support provided by Transportation Science and Technology Project of Jiangxi Provincial [Grant 2014C0001].

\section{References}

[1]. JIANG Yun-xia, CHAI Jin-yi, WU Bi-qing, et al. Research on reinforcement of hinged slab bridge without interruption [J]. Inner Mongolia Highway and Transportation, 2002 (2): 1-3.

[2]. Chen Yuechi, Wu Qingxiong, Chen Baochun. FEM ANALYSIS OF REINFORCED CONCRETE-HOLLOW SLAB REINFORCEMENT [J] .Engineering Mechanics, 2014,31 (Suppl): 51-58.

[3]. Yang Jixin. Assembled Hollow Slab Bridge Hinge Force Performance [D]. Hohhot: Inner Mongolia University of Technology, 2009.

[4]. YE Jianshu, LIU Jiusheng, YU Bo, et al. Experimental research on shear resistance of hollow slab concrete joints [J]. Journal of Highway and Transportation Research and Development, 2013,30 (06) .33-39

[5]. Yongfeng. Experimental study of hollow slab joints model [D] Xi'an: Chang'an University, 2008.

[6]. Wang Tiecheng, Xu Hui, Zhao Shaowei. Experimental study on the optimization of bridge structure [J]. Zhongnan Highway Engineering, 2006,31 (03) .45-48

[7]. TANG Xian-Xi, YIN Yue-You, GUO Wei, et al. Experimental research on the fatigue behavior of hinged slab joints [J]. Journal of Water Conservancy and Cloth Engineering, 2015,13 (01) .6-10

[8]. Wang Qu, Wu Qingxiong, Chen Baochun. Experimental research on failure modes of prefabricated hollow slab joints [J] .Engineering Mechanics, 2014,31 (Suppl), 115-120

[9]. People's Republic of China industry standard .JTG D60-2004 highway bridge design specifications [S] .Beijing: China Communications Press, 2004. 